\title{
Complex human-deer interactions challenge conventional management approaches: the need to consider power, trust, and emotion
}

\author{
Taylor R. Stinchcomb ${ }^{1}$, Zhao Ma ${ }^{1}$ and Zoe Nyssa ${ }^{2}$
}

\begin{abstract}
In the United States, the management of white-tailed deer (Odocoileus virginianus) has typically focused on improving hunting opportunities and mitigating human-deer conflicts. Yet the expansion and diversification of human communities and activities implies that human-deer interactions may also be diversifying. Approaches based on complex adaptive systems theories have been posited as a way to better attend to the diversity of these interactions between humans and wildlife. Using Indiana as a case, this study draws from the Integrated Adaptive Behavior Model (IABM) to understand human-deer interactions as a complex system. We use empirical social science to understand how citizens across Indiana perceive deer populations, what outcomes they desire, and how these perceptions could be integrated into Indiana's deer management plan. In Indiana, neither wildlife managers nor researchers have assessed public perceptions of deer beyond hunting and farming stakeholders. From May to September 2019, we collected 59 semistructured interviews and two focus groups $(\mathrm{n}=14)$ with deer stakeholders including woodland owners, farmers, deer hunters, and urban area residents. Through mixed inductive-deductive coding, we found that Indiana citizens hold complex emotions toward deer regardless of their stakeholder identity. Factors influencing these emotions include past experiences, current livelihood and behavioral contexts, beliefs about responsibilities and ethics in deer management, and beliefs about other social groups. Our results suggest that the IABM, despite adding in much-needed complexity and realism to the analysis of human-wildlife interactions, still lacks explanatory power over several important dynamics that emerged from our interviews. Here, we discuss how mixed emotions, situational context, and power dynamics challenge conventional management approaches that focus narrowly on mitigating human-deer conflicts, and that reduce public interests to demographic categorizations. To better inform social-ecological governance, models of complex human behavior should account for power within management institutions and across management scales. Our work contributes a refined understanding of how multidimensional emotions and experiences influence public (dis)interest in natural resource management, and what this implies for managers who aim to balance competing social interests with ecological conditions.
\end{abstract}

Key Words: complex systems; governance; human-wildlife interactions; North America; social-ecological systems; white-tailed deer; wildlife management

\section{INTRODUCTION}

Across the Eastern and Midwestern United States (U.S.), human interactions with white-tailed deer (Odocoileus virginianus) typify a complex and changing social-ecological system. This system exhibits multiple drivers of change, both episodic and abrupt (Holling 2001), to which human-deer interactions adjust in response (Chapin et al. 2009). Expanding human communities have created ideal "edge" habitat for deer populations to thrive (Brown and Parker 1997). At the same time, expanding deer populations impact forest ecosystem dynamics, browse on economically important crops, and increase risks of vehicle collisions and disease spread (DeNicola et al. 2000, Rooney and Waller 2003). In response, deer management continues to rely on hunting to mitigate deer-related impacts, which incentivizes the maintenance of certain deer densities (Webster and Parker 1997 , Gren et al. 2018, Serfass et al. 2018). Yet values for deer wellbeing, human-deer coexistence, and humaneness in deer management are proliferating in urban areas (Patterson et al. 2003, Manfredo et al. 2009, Dietsch et al. 2019), raising tensions between opposing social identities, ideologies, and normative behaviors like the lethal control and consumptive use of wildlife (Frank and Glikman 2019). These reciprocal feedbacks among deer, humans, and environment comprise key dynamics of complex adaptive systems (CAS; Schlüter et al. 2012) and a critical lens through which we can analyze human-wildlife interactions.
Humans thus interact with deer in a multiplicity of ways, both within a single geographic area and even within a single individual. People not only value deer differently under different contexts of human-deer interaction, but also differentially weigh the acceptability of deer management methods based on their social identity, age, gender, area of residence, beliefs about hunting, and personal experiences (Dougherty et al. 2003, Dickman 2010, Hicks 2017). For instance, Michigan hunters and farmers do not share the concerns of non-hunting and non-farming rural residents, who worry about the inhumaneness of deer hunting and risks to personal safety from large deer populations (Lishcka et al. 2008, Campa et al. 2011). In a New York suburb, male and female residents valued the consumptive use and well-being of deer differently, yet they shared values related to ecosystem protection (Lauber et al. 2001). Prior research has centered this variability around enumerable individual characteristics. Conversely, our research reveals that how people perceive deer is not entirely reducible to the demographic they occupy. In fact, certain aspects of deer become salient at different times or in different spaces for different people. Adding complexity to the system - in the sense of additional demographic variables - will not go as far toward understanding its dynamics as one might expect, because human-wildlife interactions adapt to individual, social, and ecological circumstances. 
The complexity of these social-ecological systems remains difficult to deal with in research and practice. Without an applied framework that seeks to address the cross-scalar drivers underlying public perceptions of deer as a nuisance, an asset, or something in between, human-human conflicts over deer and management approaches tend to persist (Dickman 2010, Redpath et al. 2015). Here, we draw on a conceptual model that frames human decision making as a CAS, the integrated adaptive behavior model (IABM; Jochum et al. 2014), to better characterize these drivers and their interactions in the humandeer system of Indiana. In Indiana and across the Midwestern and Eastern U.S., white-tailed deer remain the most abundant and charismatic species left on the local landscape, making them a great candidate for using the IABM lens to understand humandeer relationships and how they influence the larger socialecological system. The IABM emphasizes that human emotions and cognitions, along with contextual factors, interact dynamically to process a wildlife encounter. We find, however, that the IABM omits dynamics of (1) power asymmetry, (2) trust, and (3) emotional multiplicity that emerged as critical variables explaining when and why people express certain attitudes toward deer or deer management. Paradoxically, this "complex-systems" model serves to simplify the processes at work across cognitiveemotional and social-ecological dimensions. Throughout this paper, we seek to illuminate how researchers and managers could overcome this paradox and reconceptualize human perceptions of wildlife as adaptive and not neatly divisible into demographic categories.

\section{From conflict to complexity}

Human-wildlife interactions in North America have historically been conceptualized through a conflict lens (Dickman 2010, Frank and Glikman 2019). Concomitantly, wildlife management has emphasized the consumption and control of wild animals through recreational hunting and the lethal removal of "overabundant," "problem," or "nuisance" wildlife (Yarbrough 2015, Peterson and Nelson 2017, Dietsch et al. 2019). Recent scholarship, however, has documented a public shift toward coexistence, including increasing non-consumptive, existence, and mutualist values for wildlife (Patterson et al. 2003, Manfredo et al. 2009). The construct of human-wildlife conflict thus not only represents a visible clash between human and wildlife populations; it also comprises hidden tensions among different social groups when the needs or values of those groups are not equally represented in decision making (Patterson et al. 2003, Dickman 2010, Madden and McQuinn 2014). These humanhuman conflicts become deeply rooted in power imbalances, opposing social identities, and divergent perceptions of moral or ethical norms (Lute and Gore 2014, Peterson and Nelson 2017).

The field of human dimensions of wildlife (HDW) arose in the 1970s to help managers understand such social-ecological conflicts (Decker et al. 2012). For decades, research in HDW examined human-wildlife interactions under a cognitive hierarchy framework, where abstract values influence more specific beliefs and measurable attitudes, which are used to predict behavioral outcomes (Whittaker et al. 2006). Here, we define values as "fundamental motivational goals that influence human thought and ... behavior" (Dietsch et al. 2019:21) that tend to persist across time and contexts (Manfredo 2008). Research that focuses on attitudes and behaviors toward wildlife but neglects corresponding values therefore limits its generalizability beyond the original human-wildlife interaction (Dietsch et al. 2019). Other aspects of human cognition like emotions, personal experiences, and cultural meanings have only recently emerged as important constructs in HDW research, despite exerting evident influence on values, motivation, memory, information processing, and decision making (Izard 2007, Jacobs 2012, Sponarski et al. 2015, Jacobs and Vaske 2019).

Research on emotions within the HDW field remains sparse and primarily focused on human interactions with carnivores, which elicit negative emotions like fear and intolerance (Manfredo 2008, Jacobs and Vaske 2019). This limited attention has been partly attributed to a pervading perception in management agencies that human emotions are irrational and subjective, and partly to methodological challenges of quantifying emotional responses (Manfredo 2008, Manfredo et al. 2009, Hicks 2017). Yet scholarship in environmental anthropology (Milton 2002, West 2006), conservation psychology (Castillo-Huitrón et al. 2020), and related disciplines suggest that qualitative research using interviews, participant observation, or photo elicitation can ameliorate this by uncovering how emotions influence cognitions about wildlife and why this relationship changes across interaction contexts. As managers seek to engage more diverse publics, key questions to consider include the following: (i) how different emotions, meanings, and values related to wildlife can be balanced; and (ii) how conflict can be reduced and coexistence promoted, not only between humans and wildlife, but among diverse social groups (Jacobs and Vaske 2019). These questions require more comprehensive understanding of stakeholders' emotions toward different wildlife species, how emotions interact with cognitions to influence attitudes and behaviors, and what role social, political, and environmental factors play.

Recognizing that cognitive and emotional systems operate in a coupled, dynamic interaction, social psychologists have proposed integrated models of human decision making in response to environmental stimuli (Manfredo 2008, Jacobs 2009). One such model, IABM (Jochum et al. 2014), integrates multiple theories of human cognition into a mental system wherein cognitive, emotional, and contextual components operate simultaneously to process a wildlife encounter, assign it meaning or relevance, and influence behavioral intentions and outcomes (Fig. 1). Applied to human-wildlife interactions, these feedbacks help to explain why we express different emotions when we see a predator in the wild as opposed to in a zoo, or why some individuals feel very strong emotions when they see charismatic wildlife and others do not (Jacobs and Vaske 2019). In this model, salient personal experiences also feed back into an individual's belief system, shifting existing beliefs and attitudes toward wildlife or wildlife management. The IABM also recognizes that when and where a wildlife encounter occurs differentially influences attitudinal and behavioral outcomes. These scale components include spatial proximity to the animal, temporal proximity to the encounter, and the encounter environment. Such ecological dimensions remain crucial to consider when analyzing humanwildlife interactions (Nyhus 2016). Thus far, however, the IABM has been used very sparsely to research human-wildlife interactions in situ (Jones et al. 2016, Pooley et al. 2017, Booth and Ryan 2019). 
Fig. 1. The integrated adaptive behavior model (IABM) of human-wildlife encounters. From Jochum et al. (2014:80), Figure 2: "Yellow/light gray markings refer to components that derived originally from the Theory of Reasoned Action and the Theory of Planned Behavior. Green/medium gray markings refer to theories developed in emotions toward wildlife research. Blue/dashed marks additional components recognized in the Integrated Behavioral Model. Dark gray markings are based on Complexity Theory and components were connected by the authors. The importance of scales is displayed as overarching. The Reasoned and Reactive Route concept is based on Fuzzy Trace Theory. The Reasoned Route is based on cognitive principles (yellow/light gray arrows); the Reactive Route is based on emotional principles (green/medium gray arrows). Inhibitory and excitatory links between emotions and cognition are based on The Parallel Constraint Satisfaction Model.”

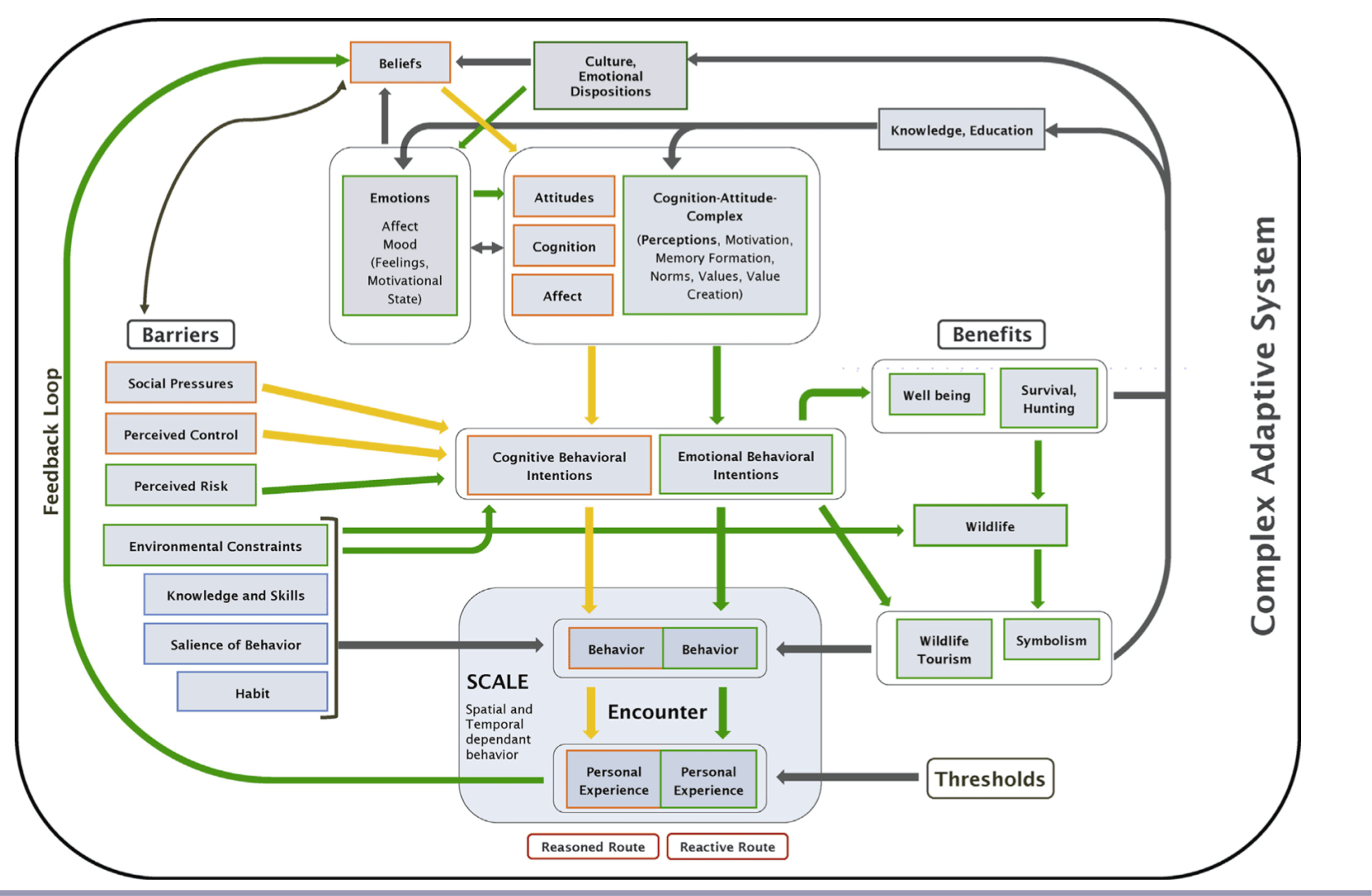

This evolution of ideas about how humans interact with wildlife reflects the complex and adaptive nature of human-wildlife systems and human-environment systems more generally. Here, we advance this thinking by applying the IABM to conceptualize individuals' perceptions of deer in Indiana as comprising multiple feedback loops among cognition, emotion, and experience, and influenced by diverse social, environmental, and scalar factors. From a management perspective, understanding the feedbacks among wildlife-related experiences, emotions, and beliefs can elucidate the social dynamics that perpetuate conflicts over wildlife. Scholars broadly agree that better understanding the dynamics of social and ecological complexity is necessary to overcome natural resource management conflicts (Liu et al 2013). Yet increasing evidence suggests that current approaches to understanding complex ecological systems do not adequately account for human perceptions, experiences, and behaviors, and thus represent fragile or even misleading sources of insight for managers (Helmreich 2000, Lansing 2000, Peterson et al. 2010). Thus, we employ the IABM as a robust tool for understanding human interactions with the environment. We also assess its limits to consider what additional factors are needed for CAS frameworks to sufficiently explain how, when, and why people perceive wildlife in different ways.

Study context: human-deer interactions in the Midwest

Across the Midwestern U.S., deer populations continue to proliferate, and human communities continue to urbanize, shifting the frequency and nature of human-deer interactions. For a variety of reasons, human-deer research and management in the region have been slow to adapt, remaining focused on the measurable impacts that deer exert on agricultural livelihoods and public health and safety. Even when experiencing these impacts, however, people enjoy seeing herbivores around their community, much more so than predators (Booth and Ryan 2019). Both negative and positive experiences unequally affect non-hunting and non-farming stakeholders (Lischka et al. 2008, Campa et al. 2011), but hunting interests still drive deer management decisions toward the maintenance of a huntable population (Jacobson et al. 2010, Serfass et al. 2018, Sullivan 2019). Accordingly, research 
on human-deer interactions has either involved only hunters and farmers or examined perceptions of hunting methods among nonhunting groups to inform a hunting-based management system (Diefenbach et al. 1997, Bath 1998).

Some human-deer research exists for Illinois (Mankin et al. 1999, Urbanek and Nielsen 2012, Urbanek et al. 2015, Hicks 2017), Ohio (Dougherty et al. 2003), and Michigan (Lischka et al. 2008, Marcoux and Riley 2010, Campa et al. 2011). Most of these studies employ surveys to quantify social perceptions of deer populations and management approaches. Only a select few have explored how gender, ethical judgements, and emotions influence beliefs about deer and evaluations of deer management decisions (Lauber et al. 2001, Dougherty et al. 2003, Hicks 2017). Their findings suggest that women tend to have greater concern than men for the unintended consequences of deer culling, like reduced access to public parks, impacts on pets or other wildlife, and noise or safety concerns (Lauber et al. 2001, Dougherty et al. 2003). Such differences suggest that cognitive processing is conditioned by prevailing gender socialization (Gilligan 1987, Noddings 1995), with women basing their "attitudes about lethal control on underlying beliefs and values, more so than male respondents" (Dougherty et al. 2003:621). Finally, Hicks (2017) provides qualitative evidence that emotional experiences pervade human reasoning about deer across public and professional spheres, but individual reflections on those emotions change with experiential learning and institutional contexts.

Few HDW studies have focused on human-deer interactions in Indiana. Corn and soybean producers have been surveyed occasionally to supplement ecological studies on crop depredation (Humberg et al. 2007). Indiana has been included in nationwide surveys on producer perceptions of wildlife-induced crop damage (Wywialowski 1994) and the acceptability of deer management methods among social groups (Messmer et al. 1997). Only a few studies have moved beyond the farming demographic to examine urban perceptions of deer and deer management (Stewart 2011, Knackmuhs and Farmer 2017). This limited literature suggests that deer-related perceptions can vary with one's identity as pro- or anti-hunting, and urban residents typically hold various concerns about the safety and ethics of deer hunting (Stewart 2011). A recent study of residents in Bloomington, Indiana, found that trust or mistrust in the city's decisions to cull deer within Griffy Lake Nature Preserve depended on how residents evaluated the decision-making process and scientific information about the preserve's deer population, as well as resident preferences for hunting and their age (Knackmuhs and Farmer 2017) Taken together, these studies suggest that perceptions and behavior are not reducible to simply demographic data.

Apart from these studies, however, the social context of humandeer interactions in Indiana remains largely unknown. More finegrained qualitative approaches are needed to understand how resident perceptions, experiences, emotions, and values related to deer vary across wider geographies and public interests. Moreover, studies should aim to move beyond descriptive surveys of deerrelated perceptions to assess the environmental, social, and cognitive factors that underlie those perceptions and drive social conflicts over deer and deer management.

\section{Research motivation and questions}

The present study follows a transition in the Indiana Department of Natural Resources (IN-DNR) under which the agency recognized a need to conduct science-based management of deer populations, including empirical social science to better understand "the desires of all Indiana residents...beyond farming landowners and hunters." (IN-DNR 2022). Until 2017, the state had collected little data on how its residents interact with deer, nor how they feel about deer populations and management. The motivation for this study is to assess the general context of deerhuman interactions across Indiana and whether and how those interactions vary among typical deer stakeholder groups. We are also interested in residents' perceptions of deer management and the changes they would like to see. Specifically, this paper addresses three interrelated research questions: (i) How do Indiana residents value, perceive, and experience white-tailed deer populations? (ii) What outcomes do they desire from deer management (and why)? (iii) What role do emotions and personal experiences play in shaping beliefs about deer and deer management?

\section{METHODS}

Conceptual framework guiding data collection and analysis Guided by the IABM, we conducted semi-structured interviews with residents across Indiana to collect data on their perceptions of, experiences with, and emotions toward white-tailed deer, and to analyze how these cognitive factors interact to influence their beliefs about deer management. Specifically, we examine how key contextual factors, such as livelihood and land management practices, components of scale, and salient political events, influence individual perceptions and emotions around deer. We then focus on the interactions of values, motivations, and experiences with emotions and how they feed back into an individual's belief system (Fig. 1). Finally, we home in on power dynamics in deer management, an emergent but highly influential factor in shaping individuals' emotions and beliefs related to deer and wildlife more broadly.

\section{Data collection and analysis}

Our research was open-ended by design and encompassed the state of Indiana to scale to state-level management practices. For our sample population, we focused on four broad deer stakeholder groups: farmers, woodland owners, urban area residents, and deer hunters. In wildlife management, the term "stakeholder" commonly refers to any individual or social group whose interest (or "stake") significantly affects or is significantly affected by wildlife and/or wildlife management decisions (Decker et al. 2012). A "stake" comprises any recreational, economic, cultural, social, or health and well-being impact or benefit derived from interacting with wildlife (Decker et al. 1996, 2012). Although hunters and farmers have been traditionally considered the primary stakeholders in deer management, we also consider woodland owners and urban area residents as stakeholders to obtain a more inclusive perspective of the impacts and benefits of deer populations in Indiana. We recognize that deer stakeholder groups are often not mutually exclusive. Yet respondents often see themselves as members of a primary group with a clear identity when it comes to deer interactions (e.g., primarily through the lens of hunter, landowner, etc.). Moreover, conventional management approaches commonly use this kind 
of categorization based on stakeholder identity. Thus, we employ traditional stakeholder categories because respondents readily self-identified as such for sampling purposes. At the same time, we use this grouping structure to test the validity of such categorizations in wildlife management through open-ended qualitative analyses, the coding strategy for which does not rest on stakeholder categorization.

We conducted 59 semi-structured interviews with deer stakeholders throughout Indiana from May to September 2019. Prior to data collection, our study design was approved by the Institutional Review Board of Purdue University. The lead author conducted all interviews either in person or over the phone, depending on the interviewee's preference. Because relatively little is known about the context of human-deer interactions in Indiana, a semi-structured approach allowed our respondents to answer our questions openly and provide detailed accounts of their deer-related views and experiences. This qualitative approach provided in-depth understanding (Henderson 1991, Mangun et al. 2007, Schutt 2018) of how different residents perceive deer populations, deer management, and their relationships to each.

Our interview protocol included questions about personal observations of deer populations and changes, experiences with and feelings about deer, and individual behaviors taken in response to deer presence or impacts. We also inquired about interviewees' experiences with the IN-DNR and deer hunters or hunting; their beliefs about deer management responsibilities and public engagement; and their desired changes for deer management in Indiana. We collected additional information about the interviewee's educational and occupational background, length of residence in Indiana, time spent in the outdoors, and general feelings toward wildlife.

To recruit study participants, we used purposive sampling to maximize representation (Creswell and Clark 2018) and snowball sampling to recruit interviewees within social groups (Neuman 2011). Both are non-probability sampling strategies commonly used in qualitative research. Together they allow researchers to recruit study participants who provide an in-depth understanding of people's emotions and experiences in their social settings (Neuman 2011, Corbin and Strauss 2015). First, we sent recruitment emails to the administrators of stakeholder organizations who then forwarded our request on to their member email lists. These organizations included the Indiana Forest and Woodland Owners' Association, the Indiana Bowhunters' Association, the Indiana Deer Hunters Conservation Alliance, the Indiana Deer Hunter Association, neighborhood associations from seven major urban areas in the state, the Indiana Farm Bureau, and Soil and Water Conservation Districts from 22 counties. We continued our sampling until we reached data saturation within each stakeholder group (Guest et al. 2006), which generally occurred at 11-13 interviews.

We also conducted two focus groups in September 2019 with residents of Bloomington, Indiana, to accommodate strong interest in participating in our study. Situated in south-central Indiana amid a heavily forested landscape, the development of Bloomington has created extensive "edge" habitat that is ideal for deer populations to forage and thrive (Brown and Parker 1997, INDFW 2011). Deer can thus be seen daily in the Bloomington area, resulting in more frequent and widespread human-deer interactions compared to cities in northern Indiana (e.g., Indianapolis, Fort Wayne, South Bend). Each focus group had seven participants, lasted about 1.5 hours, and covered the same thematic topics as our interviews.

Focus groups also allow for extended discussion among participants that add a dimension of exchange and group understanding beyond what emerges from individual interviews (Morgan 1996, Minnis et al. 1997). For instance, one resident who expressed strong mutualist values for deer acknowledged halfway through the focus group discussion that they realize the need to control deer populations for public health and safety reasons. Although shifts in opinion may be transient or subject to interpersonal dynamics in small group dialogues such as focus groups (Barbour and Kitzinger 1999), the plasticity of opinion also highlights the potential for collective processes to achieve compromise among diverse individuals on otherwise controversial issues like wildlife management. Because we did not focus our research on these interpersonal dynamics, we analyzed focus group and interview data together using the same thematic coding approach.

We first transcribed all interview and focus group recordings. We then conducted thematic analysis (Saldana 2016) of all transcripts using NVivo 12, a qualitative analysis software. Our analysis took an abductive approach, whereby our overarching themes like beliefs, emotions, experiences, behaviors, changes, and barriers were deductive (i.e., driven by our research questions and key components of the IABM), but we simultaneously allowed for new, unanticipated themes and sub-themes to emerge inductively from the interviews (DeCuir-Gunby et al. 2011). During our coding process, we implemented strategies for intercoder agreement, which involves two or more qualitative researchers reconciling their independent coding of the same text "through discussing whatever coding discrepancies they may have" (Garrison et al. 2006, Campbell et al. 2013:297). Specifically, the lead author developed the first preliminary codebook which was then used by four peer researchers and the lead author to independently code and analyze four interview transcripts. All five coders came together to discuss their coding, focusing on any incongruities in codes and interpretations that arose (Hruschka et al. 2004, Campbell et al. 2013). The lead author subsequently revised and condensed codes to reduce complexity. The codebook went through three rounds of this discursive revision process before intercoder agreement was reached. Upon agreement, the lead author finalized the codebook and applied it to code all interview transcripts. An additional coder assisted the lead author with coding the final interview transcripts, increasing the likelihood of objectivity and decreasing bias (Church et al. 2019). All thematic analysis of the coded interviews was conducted by the lead author and completed in June 2020.

\section{RESULTS}

A total of 59 individuals were interviewed (15 woodland owners, 16 hunters, 11 farmers, and 17 urban residents), and an additional 14 individuals participated in our two focus groups (Table 1). Outside of the urban resident group, all but four of our interviewees were white males (Table 1). In our final sample, the places where interviewees live and/or hunt cover a wide distribution across Indiana (Fig. 2). 
Table 1. Summary of interviewees from four deer stakeholder groups across Indiana and participants from two focus groups in Bloomington, Indiana. Semi-structured interviews were conducted May-Sep 2019 and focus groups were held on a weekend in early September 2019.

\begin{tabular}{lccc}
\hline \hline Stakeholder Group & $\mathrm{n}$ & $\%$ Male & $\%$ Female \\
\hline Woodland Owners & 15 & 93 & 7 \\
Farmers & 11 & 73 & 27 \\
Hunters & 16 & 100 & 0 \\
Urban Area Residents & 17 & 53 & 47 \\
Indianapolis & 4 & 75 & 25 \\
Greater Lafayette & 2 & 50 & 50 \\
Beverly Shores & 4 & 50 & 50 \\
Evansville & 3 & 67 & 33 \\
Bloomington & 4 & 25 & 75 \\
Subtotal (Interviewees) & 59 & 80 & 20 \\
& & & \\
Focus Group Participants & 14 & 29 & 71 \\
Group 1, Bloomington & 7 & 43 & 57 \\
Group 2, Bloomington & 7 & 14 & 86 \\
Total & 73 & 70 & 30 \\
\hline
\end{tabular}

Regardless of their stakeholder identity, many Indiana residents express mixed emotions toward white-tailed deer. These mixed emotions typically involved an appreciation or awe toward seeing deer, but frustration with deer-related damage to crops, trees, shrubs, ornamentals, or gardens, and anxiety over perceived risks to personal safety. Many interviewees also expressed a change in deer-related emotions over time. Their feelings typically shifted from excitement, novelty, or enjoyment at the sight of deer to frustration, resentment, or anxiety over the risks that deer pose, and the financial or aesthetic losses incurred from deer-related damage. Several others, who have resided in Indiana for a lifetime, shifted from awe and enjoyment upon seeing a deer to stark indifference as deer sightings became a common occurrence. Here, we explain the nuances of these changes in emotions and key factors at play in the human-deer interaction system.

Key contextual factors in the human-deer system

We found that emotions expressed toward deer depend on a suite of situational factors, including people's livelihood, involvement in land management activities, participation in environmental programs or outdoor recreation, when and where deer are encountered, prior experiences with deer or deer management, and current socio-political circumstances. The interviewee's livelihood or land management activities were seen to be the most influential factor shaping their feelings toward deer. When deer interfere with crop and timber yields or hardwood forest regeneration, they elicit frustration and blame. As one woodland owner explained, it "take[s] a lot of work and expensive money" to "replace the walnuts ... in our woods" and the deer "come up every night ... and they browse around, biting [the walnut seedlings] off" (WLO08).

Conversely, when deer minimally affect livelihoods or land management practices, landowner emotions remain largely positive or tolerant. For example, woodland owners "enjoy watching the deer" when they have "a fairly mature woods" (WLO13) while farmers who "don't raise soybeans for a living" view deer damage to non-market crops as "inconsequential" (FARM05). One farmer expressed love for "seeing the little fawns," and admitted that "I carry them out and put them in the grass ... and try and protect them" despite facing scrutiny from other farmers:

And everybody says, "Why in the devil didn't you take a
hammer and knock them in the head while you had them?"
Well, I can't do that. I can shoot them if they're eating
my beans, but I can't kill them if they're not doing
anything wrong. FARM08

Fig. 2. Counties and locations across Indiana represented by interview participants from four deer stakeholder categories: urban area residents (17 interviewees plus 7 individuals in each of two focus groups in Bloomington, IN), woodland owners (WLO; 15 interviewees), farmland owners and producers (11 interviewees), and deer hunters (16 interviewees). Locations are where participants live, manage land, and/or hunt, not necessarily where the interview took place. Many hunters hunt multiple counties. County names were given by interviewees during one-on-one interviews. WLO property sizes were also stated during interviews, and property locations were identified by landowner name and/or tax address using the online GPS mapping platform, OnX (https://www.onxmaps.com/). Resident locations represent the municipal boundaries of urban areas, downloaded from the IndianaMap public GIS database (http:// www.indianamap.org/).
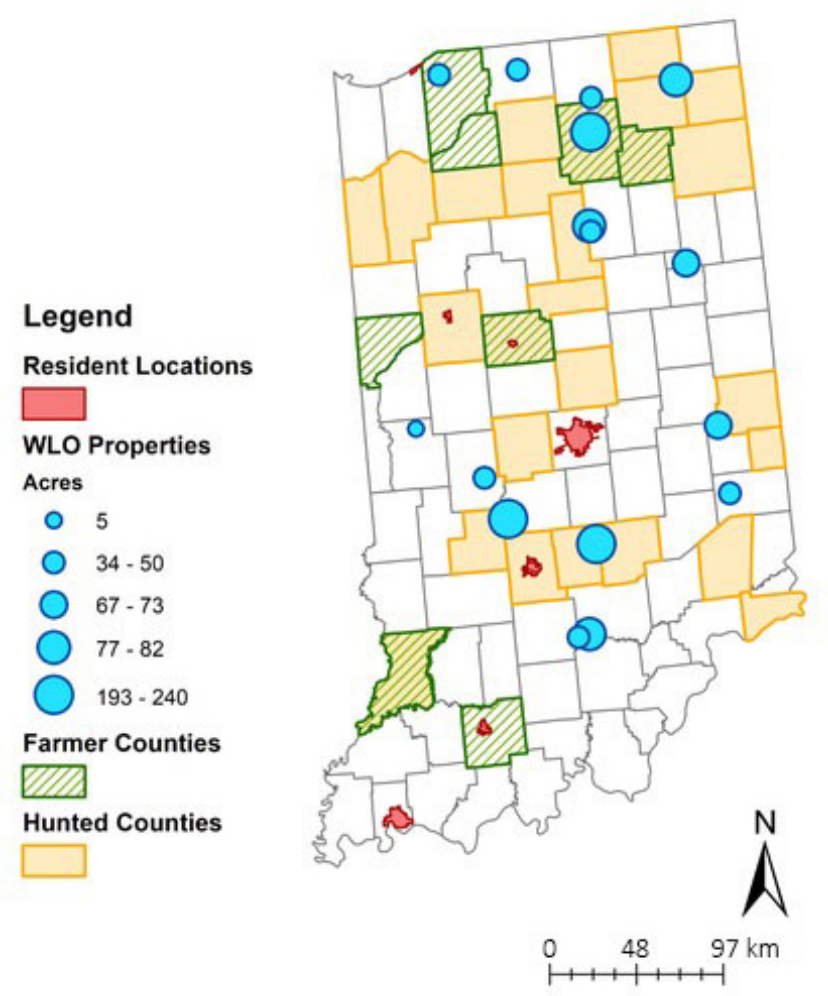
Such factors of scale - when and where an encounter occurs and the deer's age or behavior - can change landowner emotions, even when their livelihood and land management practices are impacted in different spaces or times.

Like farmers and woodland owners, urban area residents who have experienced repeated damage to their gardens or landscaping feel "hostile" when they see deer, because "the destruction of plant life is just impressive and discouraging" and they notice that deer browse on even those plants "which they're not supposed to eat" (FSGP01|S7). Concerns about health and safety risks from deer pervaded urban residents' perceptions and emotions. Urban residents tended to associate ticks (Ixodes scapularis) with an abundant deer population and expressed serious concern about the spread of Lyme disease more often than other stakeholders. Such concerns even shifted former feelings of awe and enjoyment at the sight of deer to feelings of anxiety and fear. One Bloomington resident expressed this as follows:

Well, in the beginning, I just loved it. I love seeing the
deer come. And a part of me still does... And then last
year, my dog and I were walking and we were charged by
a female deer... And after that, Ijust had huge anxieties
leaving my house with my dog and walking ... So now
personally, I have anxieties ... if [it's] only me, I'm
walking, I'm not afraid of the deer. But with my dog, I
really fear because [what] if they [the deer] feel
threatened? FSGP02|S8

Despite these anxious emotions, recent events led several interviewees to realize that, relatively speaking, managing deer may not be as important as other broader social and political issues affecting their communities. Soon after the Trump administration imposed economic sanctions on China, one farmer succinctly stated that "tariff wars kind of outweighs the deer at this point in time" (FARM02). Recalling protests at the local farmers' market that summer, a Bloomington resident expressed guilt over "even complaining about [deer] when we have a farmers market problem with racism. We have affordable housing that's a huge problem. So I don't blame them [decision makers] for not focusing on [deer management]" (FSGP01|S9). Together, these situational factors-livelihood and land management activities, space and time, public health and safety, and social-political atmospheres-show that deer-related emotions are complex, context-dependent, and subject to change. A suite of factors influences one's feelings toward deer populations, and that suite differs both within and across stakeholder groups.

\section{Feedbacks among emotion, experience, and cognition}

We see above that one's personal experiences feed back into their emotions toward deer and perceptions of deer management. Values and motivations also exert a mediating influence over deerrelated emotions and understandings. For example, holding mutualist values for the well-being of deer and striving to coexist with them influenced stakeholders' willingness to modify their land management behavior. Several urban residents spoke of changing what they plant in their yards to try to live with deer browsing, rather than prevent it. Among rural landowners, values for environmental stewardship and living close to nature interacted with their experience of minimal deer-related impacts to express an overall enjoyment or tolerance of deer populations.
One farmer put it best, explaining that deer are "a big part of who I am and how I feel and why I live where I live, and it's exciting to me [that] I see [deer] so frequently. It's interesting to me. I study them, I watch them, we have names for some of them. It's a big part of why I live where I live" (FARM05).

Hunters also expressed concern about the health of deer populations, especially related to disease outbreaks, but their concern stemmed from different motivations than those of other stakeholders. Whereas many urban area residents expressed a fundamental concern for deer well-being and existence, hunters were generally motivated to maintain a huntable population. One hunter expressed concern about chronic wasting disease (CWD) as something that "could not only affect that animal but it could affect your lifestyle" and anxiety about CWD "killing off" deer near their hunting property because "on your property you want your deer as healthy as you can get" (HUNT04). A resident of Beverly Shores made the connection that if they had ever "seen deer that were emaciated, I would feel differently about the deer cull" (RES01). An Indianapolis resident and deer hunter felt that it "would be devastating" if deer were "infected with that [chronic wasting] disease, and we wipe out a population of animals that have been here forever" so they firmly stated, "I think [deer should be managed] for the health of the ecosystem ... you lose one part, and it can have trickling down effects on other parts including humans" (RES11). For both hunters and urban residents, personal values and motivations thus influenced individual beliefs about the purpose of deer management.

\section{Power dynamics in deer management}

Introducing additional complexity into Indiana's human-deer system, we found that individuals' emotions and beliefs about deer management were driven not only by their experiences and values, but by their perceptions of power or powerlessness over deer management. A sense of powerlessness emerged among stakeholders who have experienced repeated deer-related damage and tried every approach they know to prevent it. Several said that the damage has "gotten to the point where there's nothing I can do about it" (RES05, Bloomington) and "I'm just numb to it right now" (FARM10). With exasperation, WLO13 said they do not even "know what DNR could do. Come in to scold the deer, tell them not to cross?" because the deer "move about on their own" and their behavior seems uncontrollable.

This lack of perceived control over the impacts of deer influences stakeholder beliefs about management responsibility. Among rural landowners, powerlessness over minimizing deer damage leads to beliefs that they "should be able to get rid of [deer] without repercussion" (FARM10), that the DNR has "a reputation for not being [responsive]" to landowners but being "restrictive on depredation permits" (WLO06), and that deer on private land are “our [private landowners'] responsibility and concern"(WLO11). Among urban residents, a lack of information and transparency about how authorities are currently managing deer populations also contributes to their sense of powerlessness in deer management. As one Bloomington resident said in frustration: "that seems to be a joke. I don't see any management going on" (RES05).

Urban residents possess a strong desire for management processes to involve local communities and governments because "the public elects people to take care of these things on our behalf" 
(RES09) and "[the city] wouldn't listen to me, or to [omitted], but they would [listen to] the DNR" (FSGP01|S9). If governments do not collaborate across scales, as one resident put it, "there is a lot more risk of ... not getting anything done because of controversies, local opinion. Whereas if this [deer management] is supported by county and state policies, they're more likely to get to a solution" (FSGP02|S3, Bloomington).

The sense of powerlessness also was reinforced by beliefs about hunting as neither effective nor desirable, often driven by experiences with trespassing or safety concerns about firing weapons in and around residential areas. Many rural landowners expressed an aversion to allowing hunters on their property, not only because of "instances where people obviously had been there [on the property] without our knowledge" but also because they "like to get out in the woods too during hunting season" and would question the safety of doing so (WLO11). Similarly, a resident of West Lafayette expressed concern that "there's no barrier between the forest and our house. So if somebody decides to do something stupid in the forest and start shooting, you never know" (RES13).

On the other side of this issue, Indiana deer hunters acknowledged that trespassing and poaching activities occur too often, giving hunters a poor reputation as a collective and limiting their access to private lands. Many hunter interviewees condemned such activities as irresponsible and unethical, expected other hunters to learn "how to cooperate with the farmers' expectations" (HUNT04), and expected management authorities to enforce "more strict penalties" for illegal hunting (HUNT06). Yet many hunters believed they had a personal responsibility to manage deer populations stemming from their investment in the DNR through hunting licenses and their role as the primary predator for deer in Indiana. For example, one hunter shared this:

I think we play a vital role. I can let the population get out of control if I want to ... I can shrink it by taking the does out of the herd... On the other side, I protect that herd ... We go out and actually do coyote hunts outside of deer season just to keep the coyote population down in our properties. So we do a lot to manage the herd, the herd size, the age structure of our deer, everything. HUNT02

Hunters typically shared a belief that the public does not fully understand that "the enjoyment of hunting is not the killing" (HUNT01) and hunting is necessary to "help the [deer] population" (HUNT04), which contributed to hunters' desire for the DNR to place "more emphasis on what [hunters are] saying" (HUNT03) and reduce its focus on engaging the wider public.

These quotes across stakeholder groups elucidate an iterative process in which prior experiences, or a lack thereof, with deer populations, hunting or hunters, and management, feed back into people's emotions which in turn affect their beliefs about deer and deer management. Dynamics of power and powerlessness thus comprise a critical component of mental models about deer, and one that we did not fully anticipate based on the IABM.

\section{DISCUSSION}

\section{Insights and limitations of the IABM}

Our semi-structured interviews provided a nuanced understanding of human-deer interactions across stakeholder groups in Indiana.
Using the conceptual lens of the IABM allowed us to pay close attention to individuals' experiences and emotions, which proved to be particularly useful for identifying drivers of human-deer conflicts and interpreting beliefs about deer management. Our interviews made clear that personal encounters with deer have shaped an individual's deer-related emotions, which fed back into their beliefs. These encounters, however, interact with components of scale to differentially influence how the interviewee felt toward deer as a nuisance to be controlled, an asset to protect, or something in between.

Previously, HDW scholars have identified personal experiences as important influencers of wildlife-related belief systems, value orientations, and behavioral decisions (Dickman et al. 2013, Smith et al. 2014, Kansky et al. 2016). Some acknowledge that wildlife experiences differ between residents of urban versus rural areas, who then express different behaviors or beliefs (Ericsson et al. 2018). Others have found that experiences with differing risk severities, mostly related to carnivores, affect both cognitions about the acceptability of management and emotions toward the animal (Vaske and Needham 2007, Sponarski et al. 2015). Although such regional and contextual differences have been examined, most have not included a more holistic concept of scale like that of the IABM nor been applied to non-carnivore interactions.

Scale in the IABM "consider[s] the spatial and temporal impacts on human-wildlife encounters as key components" of individuals' mental models (Jochum et al. 2014:81). Our findings expand on this understanding of scale to include the following social dimensions of deer encounters: what the individual is doing at the time of encounter (e.g., livelihood or habitual activities), whether the individual is alone or with family members or pets, and whether salient social-political events have recently occurred. The concept of scale thus highlights the importance of situational context when examining the relationships among human experiences, emotions, and values or beliefs, and their influence on wildlife-related behaviors or decisions. Indeed, situational context and place-dependency remain pillars of CAS research (Levin 1998, Rogers et al. 2013, Preiser et al. 2018). Yet the IABM fails to explicitly include ecological dimensions of situational context, including the life stage, sex, and behavior of the encountered animal (Nyhus 2016), which we found to influence when and why people hold mixed emotions toward deer. As our interviewees made clear, how people feel toward wildlife in one context may not hold in another space or time, nor between encounters with large bucks versus fawns. Even the construct of scale carries inherent complexities that if reduced to certain categories (like a generalized "deer" or "stakeholder"), will miss key drivers of people's emotions and cognitions related to wildlife.

The IABM also simplifies feedbacks among personal experiences, emotions, and environmental values, which our interviews evidenced as variable and multifaceted. Although Jochum et al. (2014) stress the importance of these feedbacks and thresholds in shifting human attitudes toward wildlife, they do not explain where or how such thresholds might be reached. Our findings align with recent quantitative work on emotional dispositions, showing that when faced with different wildlife encounter scenarios, individuals express different emotions, symbolic beliefs, and degrees of acceptability for wildlife management 
actions (Sponarski et al. 2015). Moreover, multiple experiences with similar or divergent valences interact through emotional memory (Dillard and Meijnders 2002) to "shape future thoughts, reactions, and decisions ... even attitudes and values" related to wildlife (Hicks 2014:175). Thresholds that shift one wildlife attitude to another should thus result from powerfully emotional experiences related to the circumstances of encounter, the individual's experiential history, and their underlying beliefs and value orientations toward that specific animal. In our case, individuals consistently mentioned a few memorable experiences that shaped their narrative of interacting with deer. These singular experiences within one's emotional memory represent personal touchstones, referred to recurringly in reflection and everyday conversation.

The association between human emotions and wildlife value orientations has been clearly established (Dayer et al. 2007, Larson et al. 2016, Abidin and Jacobs 2019). It was thus not surprising that deer hunters in our study, who typically orient toward wildlife domination, expressed concerns about the wellbeing of deer associated with their motivations to maintain a huntable population. In contrast, residents and landowners who expressed a fundamental concern for deer well-being were motivated by more intrinsic values for nature and wildlife existence, aligning with recent work on group identity and moral obligations to wildlife (Lute et al. 2016, Bruskotter et al. 2019). What may seem like similar concerns at the surface are influenced by different values and motivations. These underlying ethical conflicts over human-wildlife interactions drive clashes among stakeholder groups, often over perceived behaviors (e.g., inhumane hunting or trespassing), desired policy outcomes (Vining and Tyler 1999, Halpenny 2010, Wang et al. 2018), and, as our research highlights, perceived power imbalances in wildlife decision making.

\section{A need to examine power dynamics}

Previous studies have shown that along with personal experiences, emotions, and encounter contexts, power relations distinctly influence human attitudes toward wildlife (Bhatia et al. 2020). Moreover, a broad literature in political ecology has shown how viewing wildlife conflict through the lens of place, power, and politics can lead to insights into the multiplicity of perspectives and experiences individuals and communities hold. Specifically, individual perceptions of wildlife are often shaped by prior experiences with and beliefs about management agencies and government more broadly (Ingalls and Stedman 2016, Robbins 2019). In Indiana, perceived power imbalances among deer stakeholders reinforce negative perceptions about hunters by nonhunters and vice versa, which only serve to exacerbate the limitations of hunting as the primary tool for deer management. This divide presents a paradox for many states in the Eastern and Midwestern United States like Indiana in which $97 \%$ of land is under private ownership: deer management relies heavily on the cooperation of local property owners who may be increasingly skeptical of hunters and unwilling to provide access to their land. Under the North American model (NAM) of wildlife conservation (Geist 1995, Geist et al. 2001), state agencies are entrusted to manage wildlife populations and their habitat for the equal benefit of all citizens, a principle known as the public trust ideal (Decker et al. 1996, Pomeranz et al. 2014). Yet the NAM's historical foundation and legal funding structure (i.e., financial reliance on fees collected from hunting permits) have advanced the concerns of white male hunters, affording little consideration to those of non-hunters, women, and other minorities (Yarbrough 2015, Peterson and Nelson 2017). Scholars increasingly criticize the NAM for being "captured" by hunting interests (Jacobson et al. 2010, Sullivan 2019), in which wildlife managers and agencies continue to prescribe hunting as the ideal tool for wildlife management and elevate consumptive uses of wildlife over others (Feldpausch-Parker et al. 2017, Serfass et al. 2018). Recent U.S. agency efforts to engage a wider public have been deemed superficial and political, failing to integrate diverse non-hunting interests into actual decisions, and thereby generating a sense of disrespect that perpetuates social conflicts over wildlife (Madden and McQuinn 2014, Peterson and Nelson 2017).

These power imbalances embedded in the NAM remain at play within Indiana. Deer hunters expressed an elevated sense of responsibility over deer management based on their investment into the IN-DNR via license fees and their belief in hunting as a historical conservation practice. Such expectations of respect and prioritization in management decisions are shared by large-game hunters across the U.S. (Mangun et al. 2007, Vernon and Clark 2016). Conversely, non-hunting stakeholders expected the deer management decision-making process to be more inclusive and democratic, reflecting the public trust ideal (Pomeranz et al. 2014, Decker et al. 2016). When not actively engaged by wildlife managers and researchers in decision making and information exchange, non-hunting stakeholders become distrusting of a system they believe to be biased and that does not reflect their values nor experiences (Madden 2004, Zajac et al. 2012, Lute and Gore 2014). Hunters may also lose trust in management agencies when their knowledge of wildlife populations is neither solicited by managers nor reflected in management decisions (Mangun et al. 2007). For instance, several deer hunters we interviewed expressed mistrust in IN-DNR decisions when it did not specify how deer quotas or hunting zones were determined. Thus, our research highlights that stakeholder experiences with wildlife management and attendant knowledge production practices comprise a critical yet overlooked feedback loop within the IABM, one that either creates or reinforces dynamics of trust, power, and conflict in wildlife management.

Overall, the power-knowledge dynamics captured by our interviews contribute an important layer of complexity to deer and wildlife management. Complexity has traditionally implied "adding more demographics of people" to wildlife management plans, rather than envisioning the multiple and often opposing emotions, beliefs, norms, and values that one person or group simultaneously holds toward wildlife and social "others." In Indiana, for example, we found that allowing deer hunting on private lands conflicts with rural residents' desires to spend time enjoying and working the land that they legally own. Within urban spaces, the practice of hunting conflicts with perceived norms regarding the right to live safely and securely on one's property. As they become articulated in management discourses, these struggles over land rights can discredit the legitimacy of opposing groups' knowledge and deepen the rift between stakeholders (Brogden and Greenberg 2003, Robbins 2006). Thus, fundamental conflicts over whose rights, values, and experiences are reflected within management decision making could undermine the compromises required to form coalitions under 
multi-stakeholder contexts, like that of the public trust ideal (Robbins 2006).

\section{Management implications}

Power and powerlessness in deer management presents an emergent barrier that prevents deer stakeholders from expressing certain deer-related emotions or engaging in deer management behaviors. As discussed above, improving relationships and transparency between stakeholders and managers could increase trust in deer management, reduce perceptions of bias, and potentially address power imbalances among stakeholders.

Collaborative approaches that embrace a plurality of knowledge about social-ecological interactions can help move beyond powerladen conflicts and reach long-term conservation decisions (Collof et al. 2017). Because knowledge and learning comprise key feedbacks in the adaptive management of social-ecological systems (Folke et al. 2005), rethinking decision-making contexts to elevate diverse local knowledge and experiences would provide insight about potential, localized management scenarios while improving trust and transparency between agencies and their publics (Sjölander-Lindqvist et al. 2015, Riley et al. 2018, Zimmerman et al. 2021). Fostering knowledge plurality, however, is not easy; practitioners need to establish safe, neutral decision spaces where different understandings and values can be equitably expressed and peacefully negotiated (Brugnach and Ingram 2012).

Our research suggests that wildlife managers could benefit from using value-based approaches to establish a direct and iterative collaboration with diverse stakeholders, which will help to integrate abstract goals like social-ecological balance with specific strategies to reduce human-wildlife conflict (Slagle et al. 2019). Among our interviewees, many hunters, rural landowners, and urban residents expressed some sense of responsibility to care for the environment or deer populations specifically. Although these stakeholders disagreed over the ethics and safety of hunting, they generally agreed on goals of deer management: balancing the natural ecosystem, reducing deer impacts to livelihoods and land uses, and protecting the well-being of both deer and human populations. As suggested by Lute and Gore (2014), collaboratively defining a value for stewardship could help multistakeholder groups compromise on wildlife management objectives and justifications. Shared values could also overcome frequent divides between hunters and animal rights advocates, who stand at opposing ends of the wildlife value continuum (Patterson et al. 2003). It remains crucial, however, to not only identify common values but to define a collective meaning for each value and how it applies to wildlife management approaches (Patterson et al. 2003, Slagle et al. 2019).

\section{CONCLUSION}

Our findings reaffirm that human-wildlife conflicts should be understood within the local, social-ecological contexts in which they occur (Zimmerman et al. 2021) and demonstrates an approach for doing so. Case studies like ours can help to elucidate the diversity of human perceptions of and interactions with wildlife that exists within a given state or locality and the range of possible management approaches. We provided in-depth contextual descriptions to help other researchers and practitioners judge how sensible it would be to transfer our findings to similar situations (Tracy 2010, Neuman 2011). Yet our specific findings should not be assumed to apply straightforwardly and unproblematically to other contexts, even when similar cultural, natural, or socioeconomic patterns exist (Zimmerman et al. 2021). For instance, our findings represent human-deer interactions in Indiana and may not be transferrable to states with more public land and mutualism orientations or weaker hunting traditions. Critically, we acknowledge that our sample lacks racial and ethnic diversity-partly due to our sampling strategy - and thus does not reflect the knowledge of non-White populations in Indiana, nor how they might transcend typical demographic categorizations. Black, Indigenous, and People of Color (BIPOC) have historically been excluded from research and decision making in natural resource management (Yarbrough 2015, Warren 2021). Yet as the events of 2020 have brought social justice concerns to the forefront of environmental thinking (Hoover and Lim 2021), we must work harder than ever to include BIPOC perspectives in our research and practice. Future research informed by this study will attempt to capture a wider diversity of perspectives on human-deer interactions in Indiana.

Our research demonstrates that a CAS operates at the individual scale, comprising multiple, interacting components of human cognition that influence one's perceptions of deer and deer management. Although currently understudied, emotions constitute a deeply influential response to human-deer interactions that should not be passed off as irrational nor boxed into dichotomous emotions about "Bambi" versus "big bucks." These emotions mediate relationships between people's values for wildlife or nature and their beliefs about appropriate management (Sponarski et al. 2015), thus driving social conflicts over how wildlife should be managed and for whom (Redpath et al. 2015). Such power-laden conflicts have too frequently been excluded from human-wildlife and social-ecological models, yet our work highlights that perceived power imbalances influence not only human emotions and behaviors but also their trust in governance structures. Simply adding more categories of people or their responses to a model of human-wildlife interactions serves to reduce its multi-scalar complexity and its power to explain why human-wildlife or human-human conflicts persist while other interactions, like coexistence, remain elusive. Ultimately, considering human emotions and power dynamics in wildlife governance will help to realize a better balance between social and ecological well-being.

Responses to this article can be read online at: https://www.ecologyandsociety.org/issues/responses. php/12899

\section{Acknowledgments:}

This paper is a contribution of the Integrated Deer Management Project, a collaborative research effort between Purdue University and the Indiana Department of Natural Resources-Division of Fish and Wildlife. Funding was provided by the Indiana Department of Natural Resources Grant W-48-R-02. The authors thank the 
Indiana landowners and residents who participated in this study for sharing their time and knowledge.

\section{Data Availability:}

The datalcode that support the findings of this study are available on request from the corresponding author, TRS. None of the datal code are publicly available because of their containing information that could compromise the privacy of research participants. Ethical approval for this research study was granted by the Purdue University Institutional Review Board, approval number 1902021653.

\section{LITERATURE CITED}

Abidin, Z. A. Z., and M. Jacobs. 2019. Relationships between valence towards wildlife and wildlife value orientations. Journal for Nature Conservation 49:63-68. https://doi.org/10.1016/j. jnc. 2019.02.007

Barbour, R., and J. Kitzinger. 1999. Developing focus group research: politics, theory and practice. SAGE, London, UK. https://doi.org/10.4135/9781849208857

Bath, A. J. 1998. The role of human dimensions in wildlife resource research in wildlife management. Ursus 10:349-355.

Bhatia, S., S. M. Redpath, K. Suryawanshi, and C. Mishra. 2020. Beyond conflict: exploring the spectrum of human-wildlife interactions and their underlying mechanisms. Oryx 54 (5):621-628. https://doi.org/10.1017/S003060531800159X

Booth, A. L., and D. A. J. Ryan. 2019. A tale of two cities, with bears: understanding attitudes towards urban bears in British Columbia, Canada. Urban Ecosystems 22(5):961-973. https:// doi.org/10.1007/s11252-019-00873-7

Brogden, M. J., and J. B. Greenberg. 2003. The fight for the West: a political ecology of land use conflicts. Human Organization 62 (3):289-298. https://doi.org/10.17730/humo.62.3.0jdr5nte0b8vf7aw

Brown, S. E., and G. R. Parker. 1997. Impact of white-tailed deer on forest communities within Brown County State Park, Indiana. Proceedings of the Indiana Academy of Science 106(1-2):39-52.

Brugnach, M., and H. Ingram. 2012. Ambiguity: the challenge of knowing and deciding together. Environmental Science \& Policy 15(1):60-71. https://doi.org/10.1016/j.envsci.2011.10.005

Bruskotter, J. T., J. A. Vucetich, A. Dietsch, K. M. Slagle, J. S. Brooks, and M. P. Nelson. 2019. Conservationists' moral obligations toward wildlife: values and identity promote conservation conflict. Biological Conservation 240:108296. https://doi.org/10.1016/i.biocon.2019.108296

Campa III, H., S. J. Riley, S. R. Winterstein, T. L. Hiller, S. A. Lischka, and J. P. Burroughs. 2011. Changing landscapes for white-tailed deer management in the 21st century: parcelization of land ownership and evolving stakeholder values in Michigan. Wildlife Society Bulletin 35(3):168-176. https://doi.org/10.1002/ wsb. 52

Campbell, J., C. Quincy, J. Osserman, and O. K. Pedersen. 2013. Coding in-depth semi structured interviews: problems of unitization and intercoder reliability and agreement. Sociological
Methods and Research 42(3):294-320. https://doi. org/10.1177/0049124113500475

Castillo-Huitrón, N. M., E. J. Naranjo, D. Santos-Fita, and E. Estrada-Lugo. 2020. The importance of human emotions for wildlife conservation. Frontiers in Psychology 11:1277. https:// doi.org/10.3389/fpsyg.2020.01277

Chapin III, F. S., C. Folke, and G. P. Kofinas. 2009. A framework for understanding change. Pages 3-28 in C. Folke, G. P. Kofinas, and F. S. Chapin III, editors. Principles of ecosystem stewardship: resilience-based natural resource management in a changing world. Springer-Verlag, New York, New York, USA. https://doi. org/10.1007/978-0-387-73033-2 1

Church, S. P., M. Dunn, and L. S. Prokopy. 2019. Benefits to qualitative data quality with multiple coders: two case studies in multi-coder data analysis. Journal of Rural Social Sciences 34 (1):2.

Colloff, M. J., S. Lavorel, L. E. van Kerkhoff, C. A. Wyborn, I. Fazey, R. Gorddard, G. M. Mace, W. B. Foden, M. Dunlop, I. C. Prentice, J. Crowley, P. Leadley, and P. Degeorges. 2017. Transforming conservation science and practice for a postnormal world. Conservation Biology 31(5):1008-1017. https://doi. org/10.1111/cobi.12912

Corbin, J., and A. Strauss. 2015. Basics of qualitative research. Fourth edition. SAGE, Thousand Oaks, California, USA.

Creswell, J., and V. Clark. 2018. Designing and conducting mixed methods research. Third edition. SAGE, Thousand Oaks, California, USA.

Dayer, A. A., H. M. Stinchfield, and M. J. Manfredo. 2007. Stories about wildlife: developing an instrument for identifying wildlife value orientations cross-culturally. Human Dimensions of Wildlife 12(5):307-315. https://doi.org/10.1080/10871200701555410

Decker, D. J., C. C. Krueger, R. A. Baer Jr., B. A. Knuth, and M. E. Richmond. 1996. From clients to stakeholders: a philosophical shift for fish and wildlife management. Human Dimensions of Wildlife 1(1):70-82. https://doi.org/10.1080/10871209609359053

Decker, D. J., S. J. Riley, and W. F. Siemer, editors. 2012. Human dimensions of wildlife management. The Johns Hopkins University Press, Baltimore, Maryland, USA.

Decker, D., C. Smith, A. Forstchen, D. Hare, E. Pomeranz, C. Doyle-Capitman, K. Schuler, and J. Organ. 2016. Governance principles for wildlife conservation in the $21 \mathrm{st}$ century. Conservation Letters 9(4):290-295. https://doi.org/10.1111/ conl.12211

DeCuir-Gunby, J. T., P. L. Marshall, and A. W. McCulloch. 2011. Developing and using a codebook for the analysis of interview data: an example from a professional development research project. Field Methods 23(2):136-155. https://doi.

\section{org/10.1177/1525822X10388468}

DeNicola, A. J., K. C. VerCauteren, P. D. Curtis, and S. E. Hygnstrom. 2000. Managing white-tailed deer in suburban environments: a technical guide. Technical Report. Cornell Cooperative Extension; The Wildlife Society; Northeast Wildlife Damage Research and Outreach Cooperative, Ithaca, New York, 
USA. [online] URL: http://catalog.hathitrust.org/api/volumes/ oclc/46874963.html

Dickman, A. J. 2010. Complexities of conflict: the importance of considering social factors for effectively resolving human-wildlife conflict. Animal Conservation 13(5):458-466. https://doi. org/10.1111/j.1469-1795.2010.00368.x

Dickman, A., S. Marchini, and M. Manfredo. 2013. The human dimension in addressing conflict with large carnivores. Pages 110-126 in D. W. Macdonald and K. J. Willis, editors. Key topics in conservation biology 2. John Wiley \& Sons, Oxford, UK. https://doi.org/10.1002/9781118520178.ch7

Diefenbach, D. R., W. L. Palmer, and W. K. Shope. 1997. Attitudes of Pennsylvania sportsmen towards managing whitetailed deer to protect the ecological integrity of forests. Wildlife Society Bulletin 25(2):244-251.

Dietsch, A. M., M. J. Manfredo, L. Sullivan, J. T. Bruskotter, and T. L. Teel. 2019. A multilevel, systems view of values can inform a move towards human-wildlife coexistence. Pages 20-44 in B. Frank, J. A. Glikman, and S. Marchini, editors. Human-wildlife interactions: turning conflict into coexistence. First edition. Cambridge University Press, Cambridge, UK. https://doi. org/10.1017/9781108235730.005

Dillard, J. P., and A. Meijnders. 2002. Persuasion and the structure of affect. Pages 309-328 in J. P. Dillard and M. Pfau, editors. The persuasion handbook: developments in theory and practice. SAGE, Thousand Oaks, California, USA. https://doi. org/10.4135/9781412976046.n16

Dougherty, E. M., D. C. Fulton, and D. H. Anderson. 2003. The influence of gender on the relationship between wildlife value orientations, beliefs, and the acceptability of lethal deer control in Cuyahoga Valley National Park. Society \& Natural Resources 16(7):603-623. https://doi.org/10.1080/08941920309187

Ericsson, G., C. Sandström, and S. J. Riley. 2018. Rural-urban heterogeneity in attitudes towards large carnivores in Sweden, 1976-2014. Pages 190-205 in T. Hovardas, editor. Large carnivore conservation and management: human dimensions. Routledge, London, UK. https://doi.org/10.4324/9781315175454-10

Feldpausch-Parker, A. M., I. D. Parker, and E. S. Vidon. 2017. Privileging consumptive use: a critique of ideology, power, and discourse in the North American Model of Wildlife Conservation. Conservation and Society 15(1):33-40. https://doi. org/10.4103/0972-4923.201395

Folke, C., T. Hahn, P. Olsson, and J. Norberg. 2005. Adaptive governance of social-ecological systems. Annual Review of Environment and Resources 30(1): 441-73. https://doi. org/10.1146/annurev.energy.30.050504.144511

Frank, B., and J. A. Glikman. 2019. Human-wildlife conflicts and the need to include coexistence. Pages 1-19 in B. Frank, J. A. Glikman, and S. Marchini, editors. Human-wildlife interactions: turning conflict into coexistence. First edition. Cambridge University Press, Cambridge, UK. https://doi.org/10.1017/9781$\underline{108235730.004}$

Garrison, D. R., M. Cleveland-Innes, M. Koole, and J. Kappelman. 2006. Revisiting methodological issues in transcript analysis: negotiated coding and reliability. Internet and Higher Education 9:1-8. https://doi.org/10.1016/j.iheduc.2005.11.001

Geist, V. 1995. North American policies of wildlife conservation. Pages 77-129 in V. Geist, and I. M. Cowan, editors. Wildlife conservation policy. Detselig, Calgary, Alberta, Canada.

Geist, V., S. P. Mahoney, and J. F. Organ. 2001. Why hunting has defined the North American model of wildlife conservation. Transactions of the North American Wildlife and Natural Resources Conference 66:175-185.

Gilligan, C. 1987. Moral orientation and moral development. Pages 19-33 in E. F. Kittay and D. T. Meyers, editors. Women and moral theory. Rowman \& Littlefield, Totowa, New Jersey, USA.

Gren, I.-M., T. Häggmark-Svensson, K. Elofsson, and M. Engelmann. 2018. Economics of wildlife management-an overview. European Journal of Wildlife Research 64(2):22. https://doi.org/10.1007/s10344-018-1180-3

Guest, G., A. Bunce, and L. Johnson. 2006. How many interviews are enough?: an experiment with data saturation and variability. Field Methods 18(1):59-82. https://doi.org/10.1177/1525822X05279903

Halpenny, E. A. 2010. Pro-environmental behaviours and park visitors: the effect of place attachment. Journal of Environmental Psychology 30(4):409-421. https://doi.org/10.1016/j.jenvp.2010.04.006

Helmreich, S. 2000. Power/networks: a rejoinder to Lansing. Critique of Anthropology 20(3):319-327. https://doi. org/10.1177/0308275X0002000306

Henderson, K. A. 1991. Dimensions of choice: a qualitative approach to recreation, parks, and leisure research. Venture Publishing, Inc., Edmonton, Alberta, Canada.

Hicks, J. R. 2014. Mapping the connections between wildlife, learning, and emotion. Journal of Outdoor Recreation, Education, and Leadership 6(2):173-176. https://doi. org/10.7768/1948-5123.1261

Hicks, J. R. 2017. Mixed emotions: a qualitative exploration of northern Illinois whitetail deer-related decision making. Journal of Outdoor Recreation and Tourism 18:113-121. https://doi. org/10.1016/j.jort.2016.10.003

Holling, C. S. 2001. Understanding the complexity of economic, ecological, and social systems. Ecosystems 4(5):390-405. https:// doi.org/10.1007/s10021-001-0101-5

Hoover, F.-A., and T. C. Lim. 2021. Examining privilege and power in U.S. urban parks and open space during the double crises of antiblack racism and COVID-19. Socio-Ecological Practice Research 3(1):55-70. https://doi.org/10.1007/s42532-020-00070-3

Hruschka, D., D. Schwartz, D. Cobb St John, E. Picone-Decaro, R. Jenkins, and J. Carey. 2004. Reliability in coding open-ended data: lessons learned from HIV behavioral research. Field Methods 16(3):307-331 https://doi.org/10.1177/1525822X04266540

Humberg, L. A., T. L. Devault, B. J. Macgowan, J. C. Beasley, and O. E. R. Jr. 2007. Crop depredation by wildlife in Indiana. Proceedings of the National Wild Turkey Symposium 9:000:199-205. 
Indiana Department of Fish \& Wildlife (INDFW). 2011. Urban deer technical guide. Indiana Department of Natural Resources, Indianapolis, Indiana, USA.

Indiana Department of Natural Resources (IN-DNR). 2022. 2017-2022 Deer management goal. IN-DNR, Indianapolis, Indiana, USA. [online] URL: https://www.in.gov/dnr/fish-andwildlife/wildlife-resources/animals/white-tailed-deer/deer-managementand-reports/

Ingalls, M. L., and R. C. Stedman. 2016. The power problematic: exploring the uncertain terrains of political ecology and the resilience framework. Ecology and Society 21(1):6. https://doi. org/10.5751/ES-08124-210106

Izard, C. E. 2007. Basic emotions, natural kinds, emotion schemas, and a new paradigm. Perspectives on Psychological Science 2(3):260-280. https://doi.org/10.1111/j.1745-6916.2007.00044. $\underline{\mathrm{x}}$

Jacobs, M. H. 2009. Why do we like or dislike animals? Human Dimensions of Wildlife 14(1):1-11. https://doi.org/10.1080/1087$\underline{1200802545765}$

Jacobs, M. H. 2012. Human emotions toward wildlife. Human Dimensions of Wildlife 17(1):1-3. https://doi.org/10.1080/10871209.2012.653674

Jacobs, M., and J. J. Vaske. 2019. Understanding emotions as opportunities for and barriers to coexistence with wildlife. Pages 65-84 in B. Frank, J. A. Glikman, and S. Marchini, editors. Human-wildlife interactions: turning conflict into coexistence. First edition. Cambridge University Press, Cambridge, UK. https://doi.org/10.1017/9781108235730.007

Jacobson, C. A., J. F. Organ, D. J. Decker, G. R. Batcheller, and L. Carpenter. 2010. A conservation institution for the 21st century: implications for state wildlife agencies. Journal of Wildlife Management 74(2):203-209. https://doi.org/10.2193/2008-485

Jochum, K. A., A. A. Kliskey, K. J. Hundertmark, and L. Alessa. 2014. Integrating complexity in the management of humanwildlife encounters. Global Environmental Change 26:73-86. https://doi.org/10.1016/j.gloenvcha.2014.03.011

Jones, N. A., S. Shaw, H. Ross, K. Witt, and B. Pinner. 2016. The study of human values in understanding and managing socialecological systems. Ecology and Society 21(1):15. https://doi. org/10.5751/ES-07977-210115

Kansky, R., M. Kidd, and A. T. Knight. 2016. A wildlife tolerance model and case study for understanding human wildlife conflicts. Biological Conservation 201:137-145. https://doi.org/10.1016/j. biocon.2016.07.002

Knackmuhs, E., and J. R. Farmer. 2017. Factors influencing trust in a wildlife management agency: a case study of deer management in Bloomington, Indiana. Journal of Park and Recreation Administration 35(3):48-64. https://doi.org/10.18666/ JPRA-2017-V35-I3-7408

Lansing, S. 2000. Foucault and the water temples: a reply to Helmreich. Critique of Anthropology 20(3):309-318. https://doi. org/10.1177/0308275X0002000305

Larson, L. R., C. B. Cooper, and M. E. Hauber. 2016. Emotions as drivers of wildlife stewardship behavior: examining citizen science nest monitors' responses to invasive House Sparrows. Human Dimensions of Wildlife 21(1):18-33. https://doi. org/10.1080/10871209.2015.1086933

Lauber, T. B., M. L. Anthony, and B. A. Knuth. 2001. Gender and ethical judgements about suburban deer management. Society and Natural Resources 14(7):571-583. https://doi. org/10.1080/089419201750341871

Levin, S. A. 1998. Ecosystems and the biosphere as complex adaptive systems. Ecosystems 1(5):431-436. https://doi. org/10.1007/s100219900037

Lischka, S. A., S. J. Riley, and B. A. Rudolph. 2008. Effects of impact perception on acceptance capacity for white-tailed deer. Journal of Wildlife Management 72(2):502-509. https://doi. org/10.2193/2007-117

Liu, J., V. Hull, M. Batistella, R. DeFries, T. Dietz, F. Fu, T. W. Hertel, R. C. Izaurralde, E. F. Lambin, S. Li, L. A. Martinelli, W. J. McConnell, E. F. Moran, R. Naylor, Z. Ouyang, K. R. Polenske, A. Reenberg, G. de Miranda Rocha, C. S. Simmons, P. H. Verburg, P. M. Vitousek, F. Zhang, and C. Zhu. 2013. Framing sustainability in a telecoupled world. Ecology and Society 18 (2):26. http://dx.doi.org/10.5751/ES-05873-180226

Lute, M. L., and M. L. Gore. 2014. Knowledge and power in wildlife management. Journal of Wildlife Management 78 (6):1060-1068. https://doi.org/10.1002/jwmg.754

Lute, M. L., C. D. Navarrete, M. P. Nelson, and M. L. Gore. 2016. Moral dimensions of human-wildlife conflict. Conservation Biology 30(6):1200-1211. https://doi.org/10.1111/cobi.12731

Madden, F. 2004. Creating coexistence between humans and wildlife: global perspectives on local efforts to address humanwildlife conflict. Human Dimensions of Wildlife 9(4):247-257. https://doi.org/10.1080/10871200490505675

Madden, F., and B. McQuinn. 2014. Conservation's blind spot: the case for conflict transformation in wildlife conservation. Biological Conservation 178:97-106. https://doi.org/10.1016/j. biocon.2014.07.015

Manfredo, M. J. 2008. Who cares about wildlife? Springer-Verlag, New York, New York, USA. https://doi.org/10.1007/978-0-387-77040-6

Manfredo, M. J., T. L. Teel, and K. L. Henry. 2009. Linking society and environment: a multilevel model of shifting wildlife value orientations in the Western United States. Social Science Quarterly 90(2):407-427. https://doi.org/10.1111/j.1540-6237.2009.00624. $\underline{\mathrm{X}}$

Mangun, J. C., K. W. Throgmorton, A. D. Carver, and M. A. Davenport. 2007. Assessing stakeholder perceptions: listening to avid hunters of western Kentucky. Human Dimensions of Wildlife 12(3):157-168. https://doi.org/10.1080/10871200701322787

Mankin, P. C., R. E. Warner, and W. L. Anderson. 1999. Wildlife and the Illinois public: a benchmark study of attitudes and perceptions. Wildlife Society Bulletin 27(2):465-472.

Marcoux, A., and S. Riley. 2010. Driver knowledge, beliefs, and attitudes about deer-vehicle collisions in southern Michigan. Human-Wildlife Interactions 4(1):7. 
Messmer, T. A., L. Cornicelli, D. J. Decker, and D. G. Hewitt. 1997. Stakeholder acceptance of urban deer management techniques. Wildlife Society Bulletin 25(2):360-366.

Milton, K. 2002. Loving nature: towards an ecology of emotion. Routledge, London, UK. https://doi.org/10.4324/9780203421413

Minnis, D. L., R. H. Holsman, L. Grice, and R. B. Payton. 1997. Focus groups as a human dimensions research tool: three illustrations of their use. Human Dimensions of Wildlife 2 (4):40-49. https://doi.org/10.1080/10871209709359107

Morgan, D. L. 1996. Focus groups. Annual Review of Sociology 22:129-152. https://doi.org/10.1146/annurev.soc.22.1.129

Neuman, W. L. 2011. Qualitative and quantitative measurement. Pages 202-243 in Social research methods: qualitative and quantitative approaches. Seventh edition. Allyn \& Bacon, Boston, Massachusetts, USA.

Noddings, N. 1995. Care and moral education. Pages 137-148 in W. Kohli, editor. Critical conversations in philosophy of education. Routledge, New York, New York, USA.

Nyhus, P. J. 2016. Human-wildlife conflict and coexistence. Annual Review of Environment and Resources 41(1):143-171. https://doi.org/10.1146/annurev-environ-110615-085634

Patterson, M. E., J. M. Montag, and D. R. Williams. 2003. The urbanization of wildlife management: social science, conflict, and decision making. Urban Forestry \& Urban Greening 1 (3):171-183. https://doi.org/10.1078/1618-8667-00017

Peterson, M. N., and M. P. Nelson. 2017. Why the North American model of wildlife conservation is problematic for modern wildlife management. Human Dimensions of Wildlife 22 (1):43-54. https://doi.org/10.1080/10871209.2016.1234009

Peterson, R. B., D. Russell, P. West, and J. P. Brosius. 2010. Seeing (and doing) conservation through cultural lenses. Environmental Management 45(1):5-18. https://doi.org/10.1007/s00267-008-9135-1

Pomeranz, E. F., D. J. Decker, W. F. Siemer, A. Kirsch, J. Hurst, and J. Farquhar. 2014. Challenges for multilevel stakeholder engagement in public trust resource governance. Human Dimensions of Wildlife 19(5):448-457. https://doi. org/10.1080/10871209.2014.936069

Pooley, S., M. Barua, W. Beinart, A. Dickman, G. Holmes, J. Lorimer, A. J. Loveridge, D. W. Macdonald, G. Marvin, S. Redpath, C. Sillero-Zubiri, A. Zimmermann, and E. J. MilnerGulland. 2017. An interdisciplinary review of current and future approaches to improving human-predator relations. Conservation Biology 31(3):513-523. https://doi.org/10.1111/cobi.12859

Preiser, R., R. Biggs, A. De Vos, and C. Folke. 2018. Socialecological systems as complex adaptive systems: organizing principles for advancing research methods and approaches. Ecology and Society 23(4):46. https://doi.org/10.5751/ES-10558-230446

Redpath, S., S. Bhatia, and J. Young. 2015. Tilting at wildlife: reconsidering human-wildlife conflict. Oryx 49(2):222-225. https://doi.org/10.1017/S0030605314000799
Riley, S. J., J. K. Ford, H. A. Triezenberg, and P. E. Lederle. 2018. Stakeholder trust in a state wildlife agency. Journal of Wildlife Management 82(7):1528-1535. https://doi.org/10.1002/jwmg.21501

Robbins, P. 2006. The politics of barstool biology: environmental knowledge and power in greater Northern Yellowstone. Geoforum 37(2):185-199. https://doi.org/10.1016/j.geoforum.2004.11.011

Robbins, P. 2019. Political ecology: a critical introduction. John Wiley \& Sons, Hoboken, New Jersey, USA.

Rogers, K. H., R. Luton, H. Biggs, R. Biggs, S. Blignaut, A. G. Choles, C. G. Palmer, and P. Tangwe. 2013. Fostering complexity thinking in action research for change in social-ecological systems. Ecology and Society 18(2):31. http://dx.doi.org/10.5751/ ES-05330-180231

Rooney, T. P., and D. M. Waller. 2003. Direct and indirect effects of white-tailed deer in forest ecosystems. Forest Ecology and Management 181(1-2):165-176. https://doi.org/10.1016/S0378-1127 (03)00130-0

Saldana, J. 2016. The coding manual for qualitative researchers. Third edition. SAGE, Thousand Oaks, California, USA.

Schlüter, M., R. R. J. Mcallister, R. Arlinghaus, N. Bunnefeld, K. Eisenack, F. Hölker, E. J. Milner-Gulland, and B. Müller. 2012. New horizons for managing the environment: a review of coupled social-ecological systems modeling. Natural Resource Modeling 25(1):219-272. https://doi.org/10.1111/j.1939-7445.2011.00108.x

Schutt, R. K. 2018. Investigating the social world: the process and practice of research. SAGE, Thousand Oaks, California, USA.

Serfass, T. L., R. P. Brooks, and J. T. Bruskotter. 2018. North American model of wildlife conservation: empowerment and exclusivity hinder advances in wildlife conservation. Canadian Wildlife Biology \& Management 7(2):101-118.

Sjölander-Lindqvist, A., M. Johansson, and C. Sandström. 2015. Individual and collective responses to large carnivore management: the roles of trust, representation, knowledge spheres, communication and leadership. Wildlife Biology 21 (3):175-185. https://doi.org/10.2981/wlb.00065

Slagle, K. M., R. S. Wilson, J. T. Bruskotter, and E. Toman. 2019. The symbolic wolf: a construal level theory analysis of the perceptions of wolves in the United States. Society \& Natural Resources 32(3):322-337. https://doi.org/10.1080/08941920.2018.1501525

Smith, J. B., C. K. Nielsen, and E. C. Hellgren. 2014. Illinois resident attitudes toward recolonizing large carnivores. Journal of Wildlife Management 78(5):930-943. https://doi.org/10.1002/ jwmg.718

Sponarski, C. C., J. J. Vaske, and A. J. Bath. 2015. The role of cognitions and emotions in human-coyote interactions. Human Dimensions of Wildlife 20(3):238-254. https://doi. org/10.1080/10871209.2015.1010756

Stewart, C. M. 2011. Attitudes of urban and suburban residents in Indiana on deer management. Wildlife Society Bulletin 35 (3):316-322. https://doi.org/10.1002/wsb.30 
Sullivan, L. 2019. Conservation in context: toward a systems framing of decentralized governance and public participation in wildlife management. Review of Policy Research 36(2):242-261. https://doi.org/10.1111/ropr.12326

Tracy, S. J. 2010. Qualitative quality: eight "big-tent" criteria for excellent qualitative research. Qualitative Inquiry 16(10):837-851. https://doi.org/10.1177/1077800410383121

Urbanek, R. E., and C. K. Nielsen. 2012. Deer, humans, and vegetation: a case study of deer management in the Chicago Metropolitan Area. Pages 282-288 in R. M. Timm, editor. Proceedings of the 25th Vertebrate Pest Conference. University of California Davis, USA. https://doi.org/10.5070/V425110333

Urbanek, R. E., C. K. Nielsen, M. A. Davenport, and B. D. Woodson. 2015. Perceived and desired outcomes of suburban deer management methods. Journal of Wildlife Management 79 (4):647-661. https://doi.org/10.1002/jwmg.871

Vaske, J. J., and M. D. Needham. 2007. Segmenting public beliefs about conflict with coyotes in an urban recreation setting. Journal of Park and Recreation Administration 25(4):79-98.

Vernon, M. E., and S. G. Clark. 2016. Addressing a persistent policy problem: the elk hunt in Grand Teton National Park, Wyoming. Society \& Natural Resources 29(7):836-851. https:// doi.org/10.1080/08941920.2015.1080337

Vining, J., and E. Tyler. 1999. Values, emotions and desired outcomes reflected in public responses to forest management plans. Human Ecology Review 6(1):21-34.

Wang, S., Z. Leviston, M. Hurlstone, C. Lawrence, and I. Walker. 2018. Emotions predict policy support: Why it matters how people feel about climate change. Global Environmental Change 50:25-40. https://doi.org/10.1016/j.gloenvcha.2018.03.002

Warren, E. R. A. 2021. "There's not many times where people ask for your story": toward a more complete narrative reflecting experiences of environmental professionals of color. Dissertation. Texas State University, San Marcos, Texas, USA. [online] URL: https://digital.library.txstate.edu/handle/10877/13460

Webster, C. R., and G. R. Parker. 1997. The effects of white-tailed deer on plant communities within Indiana state parks. Proceedings of the Indiana Academy of Science 106 (3-4):213-232.

West, P. 2006. Conservation is our government now: the politics of ecology in Papua New Guinea. Duke University Press, Durham, North Carolina, USA. https://doi.org/10.2307/j. ctv1198x8f

Whittaker, D., J. J. Vaske, and M. J. Manfredo. 2006. Specificity and the cognitive hierarchy: value orientations and the acceptability of urban wildlife management actions. Society \& Natural Resources 19(6):515-530. https://doi.org/10.1080/08941920600663912

Wywialowski, A. P. 1994. Agricultural producers' perceptions of wildlife-caused losses. Wildlife Society Bulletin 22(3):370-382.

Yarbrough, A. 2015. Species, race, and culture in the space of wildlife management. Pages 234-253 in K. Gillespie and R.-C. Collard, editors. Critical animal geographies: politics, intersections and hierarchies in a multispecies world. First edition. Routledge, London, UK. https://doi.org/10.4324/9781315762760-7

Zajac, R. M., J. T. Bruskotter, R. S. Wilson, and S. Prange. 2012. Learning to live with black bears: a psychological model of acceptance. Journal of Wildlife Management 76(7):1331-1340. https://doi.org/10.1002/jwmg.398

Zimmermann, A., P. Johnson, A. E. de Barros, C. Inskip, R. Amit, E. C. Soto, C. A. Lopez-Gonzalez, C. Sillero-Zubiri, R. de Paula, S. Marchini, et al. 2021. Every case is different: cautionary insights about generalisations in human-wildlife conflict from a rangewide study of people and jaguars. Biological Conservation 260:109185. https://doi.org/10.1016/j.biocon.2021.109185 